\title{
Smoking enhances bone loss in anterior teeth in a Brazilian population: a retrospective cross-sectional study
}

Fernando Renó de Lima ${ }^{(a)}$ João Batista Cesar-Neto(b) Dimas Renó de Lima ${ }^{(a)}$ Warley David Kerbauy(a) Getulio Rocha Nogueira-Filho(c)

(a) Assistant Professors, Department of Diagnosis and Surgery, Division of Periodontics, School of Dentistry of São José dos Campos, São Paulo State University (UNESP), SP, Brazil.

(b) Assistant Professor, Department of Periodontics, Federal University of Pelotas, RS, Brazil.

(c) Associate Professor, Division of Periodontics, School of Dentistry, School of Medicine and Public Health of Bahia/Foundation for the Development of Science of Bahia (EBMSP/ FBDC), BA, Brazil.

\begin{abstract}
The aim of the present study was to radiographically evaluate the effect of smoking on bone loss resulting from chronic periodontitis. Periapical radiographs were analyzed of 80 patients with chronic periodontitis (40 current or former smokers and 40 never-smokers) that attended a private periodontal practice. The smokers or former-smokers with a minimum consumption of 10 cigarettes/day for a period of over 10 years were selected. Interproximal radiographic bone loss was considered as the distance between the cementum-enamel junction and the alveolar bone crest. Bone loss for smokers was higher than that observed in never-smokers $(\mathrm{p}<0.05)(3.33 \pm 1.09 \mathrm{~mm}$ and $2.24 \pm 0.76 \mathrm{~mm}$; mean \pm standard deviation for smokers and non-smokers, respectively). When each region of the mouth was comparatively evaluated, it was observed that the smokers' incisors presented the highest bone loss when compared with the other groups of teeth $(\mathrm{p}<0.01)$. Within the limits of the present investigation it can be concluded that smoking enhances the bone loss resulting from periodontitis and that the incisors are the teeth most affected.
\end{abstract}

Descriptors: Periodontitis; Bone resorption; Radiography; Smoking.

\author{
Corresponding author: \\ Getúlio Rocha Nogueira Filho \\ Fundação Bahiana para Desenvolvimento \\ das Ciências \\ Faculdade de Odontologia - FBDC \\ Divisão de Periodontia \\ Rua João das Botas, 89/901, Canela \\ Salvador - BA - Brazil \\ CEP: 40110-160 \\ E-mail:nogueira-filho@uol.com.br
}

Received for publication on Apr 24, 2007

Accepted for publication on Oct 03, 2007 


\section{Introduction}

It is widely accepted that dental biofilm plays the main role in the onset of periodontal diseases. Nevertheless, epidemiological studies have shown that the severity of periodontal breakdown varies among patients. According to Genco ${ }^{1}$ (1996), these observations lead to the hypothesis that there are local and/ or systemic risk factors, which may modulate the susceptibility to periodontitis-related tissue destruction. Among these factors, cigarette consumption has been the reason for innumerable studies over the last few years ${ }^{2-6}$ and has been considered a true risk factor for periodontitis. ${ }^{7}$

Studies have shown that smokers present greater bone $\operatorname{loss}^{5,8}$, attachment loss $\mathrm{s}^{3,8}$ and mean probing depth $^{5,9}$ when compared with nonsmokers. Grossi et al. ${ }^{8}$ (1995) showed that smokers present a higher probability of periodontal bone loss when compared with non-smokers, showing a ratio of 3.25 and 7.28 times higher for light-smokers and heavy smokers, respectively.

Data from one of the most relevant investigations regarding periodontal risk evaluating 12,329 Americans $^{10}$ showed that smoking may be responsible for more than one half of the periodontitis cases among adults in the USA. After statistical data adjustment, current smokers were about 4 times as likely as nonsmokers to have periodontitis. It has also been suggested that the number of cigarettes smoked per day ${ }^{8,11}$ and the smoking history ${ }^{12,13}$ (the number of years that the patient has smoked) are positively correlated with periodontitis severity. Although several investigations have already reported the influence of smoking on periodontitis, there is limited information with respect to a sample from Brazil. Different geographic regions normally exhibit considerable differences in demographic, environmental and possibly ecologic characteristics, factors that may influence the epidemiology of periodontitis. ${ }^{14}$ Thus, the present study aimed to radiographically investigate the effect of smoking on the severity of periodontal bone loss in a group of Brazilian patients with chronic periodontitis.

\section{Material and Methods Study population}

This study included 80 patients with chronic periodontitis from a private periodontal practice in São José dos Campos (SP, Brazil). Exclusion criteria included any systemic disorder that could affect the periodontal condition (with the exception of tobacco use, for the smoking group). According to the data collected retrospectively from the patients' files, all the patients that consumed at least 10 cigarettes per day for a period of over 10 years were included in the Smoking group (40 patients). Only patients who had never smoked were included in the Never-smoking group (Control, 40 patients). The control patients were chosen at random among the never-smokers with periodontitis. The smoking group ranged from 29 to 65 years old (mean of 44.53 years) and it was composed of 20 men (mean of 48.6 years of age) and 20 women (mean of 40.45 years of age), with a mean cigarette intake of 20.75 cigarettes/day during a mean period of 23.45 years. The never-smoking group ranged from 32 to 62 years old (mean of 44.73 years of age) and it was composed of 16 men (mean of 44.62 years of age) and 24 women (mean of 44.79 years of age).

\section{Study design}

A cross-sectional retrospective study was conducted in which 80 sets of 14 periapical radiographs (one of each patient) were analyzed before treatment for chronic periodontitis. A blind examiner performed all the measurements that were later separated in smoking and never-smoking groups. For the alveolar bone loss assessment, the cementum-enamel junction (CEJ) and the alveolar bone crest (ABC) were used as references.

\section{Radiographic data}

The radiographic sets used in the present investigation were part of the patients' periodontal documentation. Periapical radiographs were taken for all remaining teeth using EktaSpeed film (Eastman Kodak, Rochester, NY, USA) by a single radiologist using the parallelism technique (Rinn Holder, Dentsply, Weybridge, England, UK).

\section{Points of reference}

- Cementum-Enamel Junction (CEJ) - the radiographs were carefully chosen. Exclusion criteria were as follows: proximal surfaces in which the 
enamel-cementum junction was difficult to identify due to the presence of caries, restorations, prosthesis or superimposition of tooth images.

- Alveolar Bone Crest (ABC) - the ABC was considered the most coronal point along the proximal surface in which the periodontal ligament space showed a normal radiographic width, according to Papapanou, Wennström ${ }^{15}$ (1991).

\section{Measurement of alveolar bone loss}

Radiographic alveolar bone loss was determined by measuring the distance between the CEJ and $\mathrm{ABC}$ on the mesial and distal surfaces of each tooth, ${ }^{16}$ subtracting $1 \mathrm{~mm}$ (the distance found in normality). The same examiner performed all the measurements using a digital caliper (Digimess Instrumentos de Medição de Precisão, São Paulo, SP, Brazil) with a precision of one hundredth of a millimeter. The examiner was calibrated by measuring twice eight sets of radiographs ( $10 \%$ of the sample) with an interval of 1 week between each measurement session (Kap$\mathrm{pa}=0.96$ ). In order to improve measurement accuracy, the radiographs were analyzed in an X-ray film viewer with a magnifying glass.

\section{Statistical analysis}

After arithmetical determination of the bone loss for each patient, mean values for each group were obtained and statistically compared by the Student $t$ test $(\alpha=0.05)$.

\section{Results}

The 40 smokers presented 1,017 teeth, in which 1,972 proximal surfaces were evaluated; and the 40 never-smokers presented 1,046 teeth, in which 2,030 proximal surfaces were evaluated. A significant difference $(\mathrm{p}<0.05)$ was noted between the radiographic bone loss data $(3.33 \pm 1.09 \mathrm{~mm}$ and $2.24 \pm 0.76 \mathrm{~mm}$ for smokers and never-smokers, respectively) as shown in Table 1.

Similar results were observed when each group of smokers' and never-smokers' teeth was separately compared. There was a consistent significant difference $(\mathrm{p}<0.01)$ between smokers and never-smokers, and the incisors in smokers showed the greatest inter-group difference (Table 2).
Table 1 - Periodontal status parameters of smokers and non-smokers.

\begin{tabular}{l|c|c}
\hline & Smokers & Never-smokers \\
\hline Patients & 40 & 40 \\
\hline Teeth lost & $103(4.59 \%)$ & $74(3.30 \%)$ \\
\hline Teeth present & 1,017 & 1,046 \\
\hline Faces examined & 1,972 & 2,030 \\
\hline Bone loss $(\mathrm{mm})$ & $3.33 \pm 1.09^{*}$ & $2.24 \pm 0.76^{*}$ \\
\hline${ }^{*}=p<0.001$. &
\end{tabular}

Table 2 - Mean interproximal bone loss and standard deviation (in millimeters) in smoking and non-smoking patients in the different groups of teeth.

\begin{tabular}{l|c|c|c|c}
\hline \multirow{2}{*}{} & \multicolumn{2}{|c|}{ Smokers } & \multicolumn{2}{c}{ Never-smokers } \\
\cline { 2 - 5 } & Bone loss & s.d. & Bone loss & s.d. \\
\hline Molars & $3.36^{\mathrm{a}}$ & 0.44 & $2.62^{\mathrm{b}}$ & 0.49 \\
\hline Premolars & $2.70^{\mathrm{a}}$ & 0.31 & $2.08^{\mathrm{b}}$ & 0.41 \\
\hline Canines & $3.04^{\mathrm{a}}$ & 0.50 & $2.03^{\mathrm{b}}$ & 0.30 \\
\hline Incisors & $3.74^{\mathrm{a}}$ & 0.27 & $2.34^{\mathrm{b}}$ & 0.26 \\
\hline
\end{tabular}

Different letters represent significant differences $(p<0.001)$.

\section{Discussion}

The results of this study showed that the group of smokers presented higher alveolar bone resorption when compared with the never-smokers, especially in the anterior teeth (incisors), and confirmed that cigarette consumption may act as an aggravating factor in periodontitis. The present finding is in agreement with that of previous studies conducted in other populations that showed that cigarette consumption was detrimental to periodontal tissues. $^{3,6,17}$

Several studies have used radiographs to comparatively evaluate periodontal bone loss in smokers and non-smokers. ${ }^{4,6,15,18}$ It is, however, difficult to establish a parallel among studies because of the methodological differences in bone loss evaluation. Longitudinal studies often express the marginal bone level as the ratio between the apex-alveolar crest and apex-cementoenamel junction distance. ${ }^{4,6,18}$ The present investigation was based on the methodology proposed by Schüller, Holst ${ }^{16}$ (2001) (which considered alveolar bone loss as the 
distance between CEJ an $\mathrm{ABC}$ ), including the subtraction of $1 \mathrm{~mm}$, which is the CEJ-ABC distance found in normality. A similar method may enable comparisons between the studies. Both studies observed that smokers presented an increased bone loss when compared with non-smokers, but the bone loss values obtained in the present investigation $(3.33 \pm 1.09 \mathrm{~mm}$ and $2.24 \pm 0.76 \mathrm{~mm}$ for smokers and nonsmokers, respectively) were higher than those observed by Schüller, Holst ${ }^{16}$ (2001) $(2.64 \mathrm{~mm}$ for smokers and $1.51 \mathrm{~mm}$ for nonsmokers). The differences as regards bone level may be explained, at least partially, by three factors:

1. the present investigation evaluated only patients with chronic periodontitis, while Schüller, Holst ${ }^{16}$ (2001) evaluated randomly chosen patients, without taking into consideration the clinical diagnosis of periodontitis;

2. Schüller, Holst ${ }^{16}$ (2001), in their study, used bitewing radiographs, while periapical radiographs were used in the present study, and

3. the demographic and socio-economic differences between the samples.

In addition, the degree of cigarette consumption was an inclusion criterion for this study (minimum of 10 cigarettes/day for more than 10 years) and may have influenced the present findings, since Grossi et al. ${ }^{8}$ (1995) showed that periodontal destruction is directly proportional to cigarette consumption. The present study is in line with most of the studies in the literature, which, regardless of the methodological differences, showed a detrimental effect of smoking on periodontal health.

A harmful effect of smoking was also noted when each group of teeth in the control group was compared with its corresponding region in the test group. The highest difference between the groups was observed for the incisors (showing bone loss values of $3.74 \mathrm{~mm}$ and $2.34 \mathrm{~mm}$, for smokers and never-smokers respectively) probably because of the direct effect of smoke on the incisor area. These results are in agreement with those of the study by Haffajee, Socransky ${ }^{13}$ (2001), which clinically evaluated the attachment loss in smokers and non-smokers and showed a greater attachment loss for smokers' incisors. On the other hand, a recent study of Laurell et al. ${ }^{19}$ (2003) did not find an accentuated effect of smoking in a particular area and related that loser sites in smokers appear at random. Thus, further studies are necessary in order to better elucidate the impact of smoking on particular groups of teeth.

The mechanisms by which smoking affects periodontal destruction are not fully understood. From in vitro studies, it has been reported that bacteria are selectively affected by cigarette smoke ${ }^{20}$ and that smokers present a decreased oxygen tension in periodontal pockets, which could favor anaerobic colonization. ${ }^{21}$ In contrast, clinical studies have shown minor differences between smokers and nonsmokers with respect to periodontal microflora. ${ }^{22}$ Evidence has suggested that smoking may enhance periodontal breakdown by affecting host response. Neutrophils are the first line of defense against bacterial infection, and have demonstrated an impaired function in smokers, showing a decreased chemotaxis, ${ }^{23}$ phagocytosis, ${ }^{24}$ and adherence. ${ }^{24}$ Additionally, cigarette smoke compounds negatively affected gingival fibroblast attachment and proliferation in vitro $^{25}$ and higher levels of MMP-2 were found in gingival tissue adjacent to periodontitis sites in rats submitted to cigarette smoke inhalation. ${ }^{26}$ These findings may offer a biological basis to the clinical observations in the present study.

It is well recognized that different geographic regions normally exhibit considerable differences in demographic, environmental, genetic, ethnic and possibly ecologic characteristics, which may cause and aggravate periodontal diseases. ${ }^{14}$ Thus, it is difficult to compare epidemiological data from developed countries (which are the source of most of the studies) with data from developing countries. This aspect highlights the importance of investigating each specific population. One of the only studies focused on Brazilians investigated an urban population in southern Brazil (853 dentate subjects), and showed that smoking is strongly correlated with severe attachment loss. ${ }^{27}$ The present study data are in line with those previously observed for the Brazilian population, and, as far as the authors know, this is the first study that investigated patients of a private periodontal practice.

A series of recent studies published by the group 
of Bergström and Baljoon in Saudi Arabia patients mainly compared the effects of cigarette smoking and water pipe smoking in periodontal vertical bone loss measured by full sets of radiographs. ${ }^{28}$ The impact of water pipe smoking (that had a sharp rise consumption by the popularity in the recent years by men and women in Middle East countries) is of the same magnitude as that of cigarette smoking. They concluded that tobacco smoking should be considered a risk factor for periodontal vertical bone loss, ${ }^{28,29}$ indicating a significant long-term influence of smoking on vertical periodontal bone loss, and yielding additional evidence that smoking is a risk factor for periodontal bone loss. ${ }^{30}$

\section{References}

1. Genco RJ. Current view of risk factors for periodontal diseases. J Periodontol. 1996;67(10 Suppl):1041-9.

2. Alpagot T, Wolff LF, Smith QT, Tran SD. Risk indicators for periodontal disease in a racially diverse urban population. $\mathrm{J}$ Clin Periodontol. 1996;23(11):982-8.

3. Axelsson P, Paulander J, Lindhe J. Relationship between smoking and dental status in 35-, 50-, 65-, and 75-year-old individuals. J Clin Periodontol. 1998;25(4):297-305.

4. Bergstrom J, Eliasson S, Dock J. A 10-year prospective study of tobacco smoking and periodontal health. J Periodontol. 2000;71(8):1338-47.

5. Bergstrom J, Eliasson S, Preber H. Cigarette smoking and periodontal bone loss. J Periodontol. 1991;62(4):242-6. Erratum in: J Periodontol. 1991;62(12):809.

6. Bolin A, Eklund G, Frithiof L, Lavstedt S. The effect of changed smoking habits on marginal alveolar bone loss. A longitudinal study. Swed Dent J. 1993;17(5):211-6.

7. Consensus report. Periodontal diseases: epidemiology and diagnosis. Ann Periodontol. 1996;1(1):216-22.

8. Grossi SG, Genco RJ, Machtei EE, Ho AW, Koch G, Dunford $\mathrm{R}$ et al. Assessment of risk for periodontal disease. II. Risk indicators for alveolar bone loss. J Periodontol. 1995;66(1):239.

9. Haber J, Kent RL. Cigarette smoking in a periodontal practice. J Periodontol. 1992;63(2):100-6.

10. Tomar SL, Asma S. Smoking-attributable periodontitis in the United States: findings from NHANES III. National Health and Nutrition Examination Survey. J Periodontol. 2000;71(5):743-51.

11. Krall EA, Dawson-Hughes B, Garvey AJ, Garcia RI. Smoking, smoking cessation, and tooth loss. J Dent Res. 1997;76(10):1653-9.
With respect to periodontal health, it appears that just as with subjects in developed countries, the negative effects of smoking also influence Brazilians. Further studies should, however, be considered in order to investigate whether these similarities continue to be present in the long-term, and whether smoking affects each population to a similar extent and severity.

\section{Conclusion}

Within the limits of the present investigation it can be concluded that smoking may enhance the bone loss resulting from periodontitis and that the incisors are the teeth most affected.

12. Grossi SG, Zambon JJ, Ho AW, Koch G, Dunford RG, Machtei EE et al. Assessment of risk for periodontal disease. I. Risk indicators for attachment loss. J Periodontol. 1994;65(3):2607.

13. Haffajee AD, Socransky SS. Relationship of cigarette smoking to attachment level profiles. J Clin Periodontol. 2001;28(4):283-95.

14. Nunn ME. Understanding the etiology of periodontitis: an overview of periodontal risk factors. Periodontol 2000. 2003;32(1):11-23.

15. Papapanou PN, Wennstrom JL. The angular bony defect as indicator of further alveolar bone loss. J Clin Periodontol. 1991;18(5):317-22.

16. Schuller AA, Holst D. An "S-shaped" relationship between smoking duration and alveolar bone loss: generating a hypothesis. J Periodontol. 2001;72(9):1164-71.

17. Norderyd O, Hugoson A. Risk of severe periodontal disease in a Swedish adult population. A cross-sectional study. J Clin Periodontol. 1998;25(12):1022-8.

18. Jansson L, Lavstedt S. Influence of smoking on marginal bone loss and tooth loss - a prospective study over 20 years. J Clin Periodontol. 2002;29(8):750-6.

19. Laurell L, Romao C, Hugoson A. Longitudinal study on the distribution of proximal sites showing significant bone loss. J Clin Periodontol. 2003;30(4):346-52.

20. Bardell D. Viability of six species of normal oropharyngeal bacteria after exposure to cigarette smoke in vitro. Microbios. 1981;32(127):7-13.

21. Hanioka T, Tanaka M, Takaya K, Matsumori Y, Shizukuishi S. Pocket oxygen tension in smokers and non-smokers with periodontal disease. J Periodontol. 2000;71(4):550-4.

22. Darby IB, Hodge PJ, Riggio MP, Kinane DF. Microbial comparison of smoker and non-smoker adult and early-onset 
periodontitis patients by polymerase chain reaction. J Clin Periodontol. 2000;27(6):417-24.

23. Kraal JH, Kenney EB. The response of polymorphonuclear leukocytes to chemotactic stimulation for smokers and nonsmokers. J Periodontal Res. 1979;14(5):383-9.

24. Kenney EB, Kraal JH, Saxe SR, Jones J. The effect of cigarette smoke on human oral polymorphonuclear leukocytes. J Periodontal Res. 1977;12(4):227-34.

25. Cattaneo V, Cetta G, Rota C, Vezzoni F, Rota MT, Gallanti A et al. Volatile components of cigarette smoke: effect of acrolein and acetaldehyde on human gingival fibroblasts in vitro. $\mathrm{J}$ Periodontol. 2000;71(3):425-32.

26. Cesar Neto JB, de Souza AP, Barbieri D, Moreno H Jr, Sallum EA, Nociti FH Jr. Matrix metalloproteinase-2 may be involved with increased bone loss associated with experimen- tal periodontitis and smoking: a study in rats. J Periodontol. 2004;75(7):995-1000.

27. Susin C, Oppermann RV, Haugejorden O, Albandar JM. Periodontal attachment loss attributable to cigarette smoking in an urban Brazilian population. J Clin Periodontol. 2004;31(11):951-8.

28. Natto S, Baljoon M, Bergstrom J. Tobacco smoking and periodontal bone height in a Saudi Arabian population. J Clin Periodontol. 2005; 32(9):1000-6.

29. Baljoon M, Natto S, Bergstrom J. The association of smoking with vertical periodontal bone loss. J Periodontol. 2004;75(6):844-51.

30. Baljoon M, Natto S, Bergstrom J. Long-term effect of smoking on vertical periodontal bone loss. J Clin Periodontol. 2005;32(7):789-97. 